\title{
From a SharePoint-Based E-Learning System to Moodle
}

\author{
Bernd Decker \\ RWTH Aachen University \\ Aachen Germany \\ decker@itc.rwth-aachen.de
}

\author{
Marius Politze \\ RWTH Aachen University \\ Aachen Germany \\ politze@itc.rwth-aachen.de
}

\author{
Sarah Grzemski \\ RWTH Aachen University \\ Aachen Germany \\ grzemski@itc.rwth-aachen.de
}

\begin{abstract}
A Moodle-based e-learning system will replace RWTH Aachen University's SharePoint-based e-learning system, which was introduced 10 years ago, within the course of digitizing teaching processes. The strategic background for the university management is that in the competition for students, teaching must become more attractive through innovative formats. At the same time, students demand the support of new, state of the art teaching scenarios and formats.

In contrast to the old SharePoint-based LMS solution, there is a large Moodle community at German universities that actively promotes developing Moodle further according to university-specific requirements. Through the collaborative development of Moodle within the community, interests can be pooled, meaning individual efforts can be reduced and a sustainable and quality-assured development of the LMS can be guaranteed.

Within the context of introducing a new e-learning platform, not only technical challenges arose but numerous organizational and procedural changes surfaced as well. Additionally, the stakeholders wanted to keep the operation and functionalities close to the old system in order to make the transition for users as simple as possible, while at the same time, developing a modern platform with up-to-date user guidance and innovative teaching formats.
\end{abstract}

\section{CCS CONCEPTS}

- Applied computing $\rightarrow$ Learning management systems; $\bullet$ Information systems $\rightarrow$ Information systems applications; • Software and its engineering $\rightarrow$ Software creation and management;

\section{KEYWORDS}

Moodle, digitizing teaching processes, collaborative development

\section{ACM Reference Format:}

Bernd Decker, Marius Politze, and Sarah Grzemski. 2018. From a SharePointBased E-Learning System to Moodle. In 2018 ACM SIGUCCS Annual Conference (SIGUCCS '18), October 7-10, 2018, Orlando, FL, USA. ACM, New York, NY, USA, 6 pages. https://doi.org/10.1145/3235715.3235720

\section{INTRODUCTION}

With the introduction of the teaching and learning portal L2P [3] as the central Learning Management System (LMS), a seamless integration with the Campus Management System [4] and low-threshold

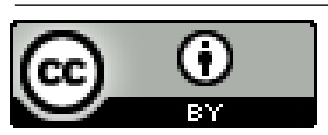

This work is licensed under a Creative Commons Attribution International 4.0 License.

(c) 2018 Copyright held by the owner/author(s).

ACM ISBN 978-1-4503-5582-7/18/10.

https://doi.org/10.1145/3235715.3235720 support for blended learning was established at RWTH Aachen University in 2006. Within a few semesters, a broad permeation with virtual courses was achieved. Currently $73 \%$ of all lectures use a virtual learning room. In total, approximately 3000 virtual learning rooms are created each semester. Besides the integration into the central IT systems of the university, a low-level handling was an important factor for the success of the LMS. In order to achieve the low level in the use of the LMS, the system was limited to basic, simple, generally usable and seamlessly integrated functionality. Accordingly, the main activities in LMS were the exchange of digital content (pdf, docx) and information in the form of e-mail, announcements or hyperlinks.

When the LMS was introduced in 2006, the aim was to integrate blended learning into established IT structures and teaching processes. There should be support for classroom teaching which can be used widely throughout RWTH Aachen University. A low entry hurdle was primarily ahead of advanced e-learning scenarios. The original goal of establishing blended learning at RWTH Aachen University was achieved, the use of the LMS is widespread. In the context of the digitization of teaching, the orientation of the strategy has changed for a variety of reasons [1]. It is now the aim to support a wide range of blended learning formats. The overriding goal of the digitization strategy is to create optimal conditions for excellent teaching and learning at RWTH Aachen University. In this context, the entire range of didactically meaningful blended learning formats will be encouraged in all faculties of RWTH Aachen University [5].

The new strategic orientation of the university has led, among other things, to the fact that the university has dealt conceptually with which system is the right technological basis for the LMS of the future. The former LMS L2P was developed on the basis of Microsoft SharePoint ${ }^{1}$. SharePoint is a collaboration platform and very well suited for the exchange of information, digital content, etc. but not a real learning management system with deeper blended learning functionalities in the context of teaching. This was the decisive reason why RWTH Aachen University decided to change the system. After an analysis of the current LMS at German universities, Moodle ${ }^{2}$ was chosen as the future LMS. In addition to focusing on the topic of Blended Learning, Moodle offers further advantages for RWTH Aachen University, in contrast to the SharePoint-based LMS solution, there is a large Moodle community at German universities that actively promotes developing Moodle further according to university-specific requirements. These include implementing the new European General Data Protection Regulation, as well as topics like learning analytics and improvements in user experience. Through the community, Moodle has a very large number of developers, more than most of the proprietary LMS vendors. By

\footnotetext{
${ }^{1}$ https://products.office.com/en-US/sharepoint/collaboration

${ }^{2}$ https://moodle.org/
} 


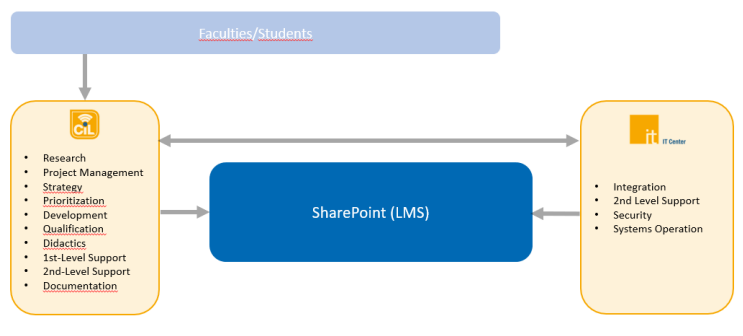

Figure 1: Organizational structures in the past

(permitted and desired) use of foreign code, this is subjected to an above-average number of reviews. This enables errors to be found and corrected very quickly.

The community also offers an easy way to get support, exchange ideas and meet others within the community.

In mid-2017, the RWTH Aachen officially decided that the technological basis of the LMS would be replaced by Moodle instead of SharePoint. However, the resolution also sets out a few boundary conditions for the project. The entire university-wide change-over is to take place within two years. During this time, the system is to be extended to include RWTH-specific requirements and the RWTH is to become a front-runner in the field of Moodle-based LMS in Germany.

\section{ORGANIZATIONAL CHANGES}

In addition to the changes in the technical basis of the LMS, organizational changes were also decided. In the former model, the e-learning department of RWTH Aachen University was responsible for the strategy, further development and support for all LMSrelated issues. This department was affiliated to a chair of computer science. A very close integration of research and services was desired, in which research plays a key role.

In the meantime, the university has come to realize that the close integration of research and services is not effective. The LMS has become an integral part of teaching and users' expectations regarding points that are not the primary focus of computer science research, such as service and reliability, have increased. In the course of the conversion of the LMS basis from SharePoint to Moodle, the allocation of responsibilities between the specialist department, IT Center and university committees will therefore also be newly regulated. The baseline of the new structure is a greater separation of research and services. In addition to research, support, consulting and communication, the work in the specialist department has so far focused on conception and development. The tasks of the IT Center were integration into the RWTH Aachen University system landscape (campus management, identity management, third party systems) and operation of the platform. Within this framework, the specialist department developed the platform features, the IT Center develops in the area of integration into university IT. Project management for feature development and product responsibility was in the specialist department, operational responsibility at the IT Center. All necessary arrangements were made in weekly meetings. In the planned model, integration and operation will remain with the IT Center, while the specialist department will continue to be responsible for research, consulting, qualification and in some cases communication. With regard to development work and support, however, the dividing line between the task areas has been shifted. Software development, 1st level support, project management and product responsibility are now the domain of the IT Center.

\subsection{Software Development}

The change in responsibilities also affects the distribution of roles in software development. Previously, the development of the features for the platform was in the hands of the specialist department, only the deployment processes had to be coordinated with the IT Center. For the integration into the central systems of RWTH Aachen University, the specialist department formulated requirements, which were independently mapped to the system and implemented by the IT Center. For the development of extensions for Moodle, the software development process is now the responsibility of the IT Center. The specialist department then functions more as a kind of client who specifies the requirements and priorities, while the IT Center contributes the know-how for software development to the project.

The relocation of development to the IT center makes it easier to react to personnel bottlenecks in the area of software development. In addition, the proximity of system operation and software development brings advantages in cooperation.

\subsection{Support}

The 1st level support and thus also the direct contact to the users was performed completely by the specialist department so far. In future, the IT Servicedesk of the IT Center will function as a single point of contact and will be available to users for all questions relating to the LMS. The IT Servicedesk can be contacted by phone, e-mail, chat and in person. Further support cases are handed over to 2 nd level support. The 2 nd level support is provided jointly by the business department, the system operators and the software developers. Technical problems are handled by the IT Center (developers/operators) and questions on the topic e-learning by the specialist department. However, the postponement of the tasks also results in changes here. Up to now, the IT Center was only involved in the areas of system operation and integration in 2nd level support, but in future all further questions regarding the developed software will also end up in the IT Center. Like in other IT Center cooperation models [2], this also opens up new ways of communication (Figure 2).

Joint internal and external documentation must be established and the external presentation (blog, Facebook, etc.) must be coordinated.

\subsection{University-wide structures}

In addition to the reorganization of direct responsibility for the LMS and support, the processes for the strategic further development of the LMS will also be redefined. While the specialist department has so far largely decided on its own in which direction the LMS will be further developed, the strategic development of the platform is now controlled by the RWTH Blended Learning Steering Group. The Board plans and controls the strategic orientation of the LMS and prioritizes the integration and development of new features into the platform. 


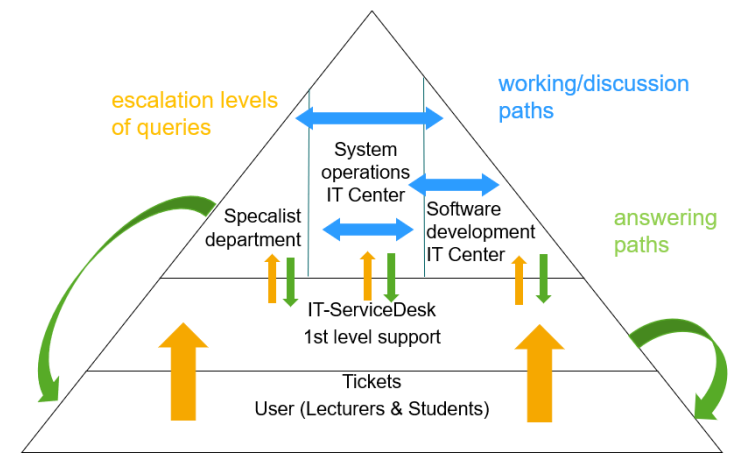

Figure 2: New support structures

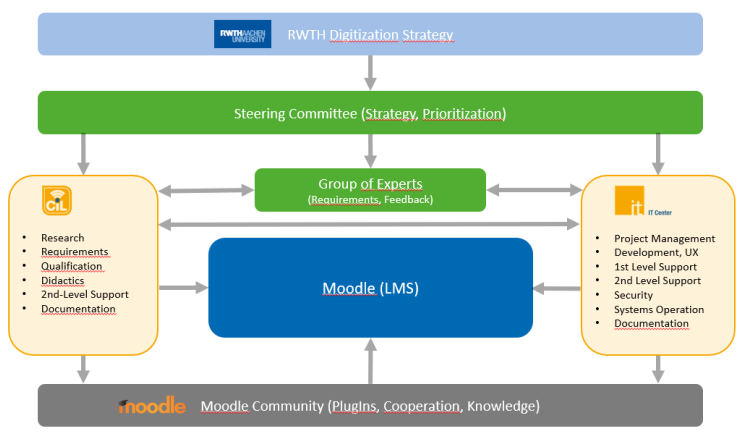

Figure 3: Planned organizational structures

The inclusion of the steering group ensures that it is embedded in the overall digitization strategy of RWTH Aachen University. The Blended Learning steering group will also establish a panel of experts consisting of representatives of the faculties and students. This round ensures continuous and close accompaniment of the further development of the system by the actual users. At the same time, the regular interaction serves communication and transparency in the direction of the faculties and students.

\section{ROLLING OUT MOODLE}

The complete migration to Moodle as LMS is scheduled for a period of two years. After this time, new virtual learning rooms will be created exclusively in Moodle. The SharePoint based system will then be operated in parallel for another two years, so that students will still have access to the learning materials of their courses. There are no plans to migrate digital content from SharePoint to Moodle. On the one hand, this would be technically a very complex task and on the other hand, it is hardly possible to map a virtual learning room from SharePoint to Moodle. Instead, an interface between the systems is developed so that lecturers can import digital content from the legacy system into Moodle via a graphical interface. The changeover is to take place iteratively and is divided into four phases.

\subsection{Winter semester 2017/18 - Phase one}

The first phase of the project started in the winter semester 2017/18, relatively shortly after the decision to switch to Moodle and to reorganize. Due to the short time available, the planned new organizational structures have not yet been applied in this phase.

The goal of the phase was to get feedback from users on the features included in the standard Moodle package, build up Moodle know-how and get initial feedback from users on problems with the use of Moodle. At the same time, concepts for the interaction in the new allocation of responsibilities between the IT center and the business department were to be developed and experience gained in the development of the first plug-ins for phase two.

Technically, a standard Moodle with a few selected plug-ins in version 3.2 was provided in the winter semester 2017/18. In this phase, the system was also integrated into the SharePoint based LMS. So that the users had an entry point, no matter which of the two LMS systems was used for teaching and the existing connection to Identity Management and the Campus Management System could also be used for SharePoint and Moodle. For this phase, lecturers from 15 courses were convinced to use Moodle instead of SharePoint in their lectures. The courses are spread across all faculties in order to receive comprehensive feedback.

\subsection{Summer semester 2018 - Phase two}

The aim of this phase, which is currently running, is to gain more in-depth experience with Moodle. Especially in the areas of software development and operation. For this purpose, users are provided with an independent system that is no longer linked to the SharePoint based LMS. The connection to the Identity Management System was changed to Shibboleth and Moodle was also connected directly to the Campus Management System. In this way, the virtual learning rooms can be created directly from the Campus Management System and the lecturers and students associated with the course can be automatically synchronized to the correct virtual learning rooms.

First plugins, which were developed in phase one, are used and tested by the users. The in-house developments concern the topics user experience, data protection as well as roles and rights.Moodle should already cover the complete functionality of the old LMS in this phase. To achieve this goal, community plugins are used. A total of 15 plugins are used in the summer semester 2018.

In the second phase, the reorganisation of the processes in the areas of software development and support will also be carried out.The specialist department now defines requirements for the system which are implemented in the IT Center by the developers and system operators. The 1st level support now runs via the ITServiceDesk as single point of contact for the users. From there, the requests are then routed to the different second level teams if required. The existing online Moodle documentation is used as documentation for the users, no additional user documentation is created. Instead, video tutorials and tours are created by Moodle that guide users through the system the first time they log in to Moodle. In order to receive structured feedback on Moodle, there are still regular online surveys and interviews.

About 50 courses use Moodle as LMS in this phase.

As in the first phase, the system will be further adapted in the 
summer semester 2018, taking user feedback into account, and additional plug-ins will be developed to be used in phase three.

\subsection{Winter semester 2018/19 - Phase three}

Phase three will start in the winter semester 2018/19 with the aim of using the knowledge gained in phase two to further adapt the system and further optimize cooperation between the specialist department and the IT Center. In this phase, cooperation with teachers and students will be intensified. There will also be online surveys, interviews and user tests on working with Moodle. In addition, the panel of experts, which is to be closely involved in the further development of the system, will be instantiated. Furthermore, the plugins developed in phase two will be used and evaluated. Parallel to the conversion of the LMS to Moodle, a new Campus Management System is being introduced at RWTH Aachen University. The system will go live in the winter semester 2018/2019, so that the connection to the Campus Management System has to be newly implemented for phase three and used for the first time in this phase. The documentation will be further expanded and new training courses for users will be designed and offered. In addition, university-wide information events are planned to inform users about planned changes. In this phase, the entire Faculty of Construction Engineering will use Moodle as its LMS. In the past, the Faculty of Construction Engineering used an average of 175 virtual learning rooms per semester.

\subsection{Summer semester 2019 - GoLive}

With the GoLive in the summer semester 2019 the switch to Moodle and thus also the project will be completed. All new virtual learning rooms will be created exclusively in Moodle this semester. The SharePoint-based LMS will continue to be operated for another two years so that students will continue to have access to the learning materials stored there. Support processes for SharePoint remain with the specialist department as in the former model. The governance structures for working with Moodle are expected to be established by then and the further development of Moodle will continue as a service of the IT Center.

\section{EVALUATION}

After completion of the first phase in winter semester $17 / 18$, students were asked about their experiences with Moodle in an online survey and lecturers were interviewed. 160 students answered the survey in full and eight lecturers were available for an interview. Although Moodle was used in this phase with almost no adjustments, the lecturers only received a brief introduction and the students were not even introduced to its operation, the feedback was generally more positive than expected. When evaluating the students' answers, it must be taken into account that the design of the virtual courses by the lecturer also has an influence. Moodle offers lecturers much more design freedom than SharePoint, but in order to make the most of these possibilities, lecturers must first gain experience with the system.

Students found Moodle easy to learn to use and although users are used to a different system, Moodle behaves according to users' expectations (fig: 4).

At the same time, there was also feedback indicating that users

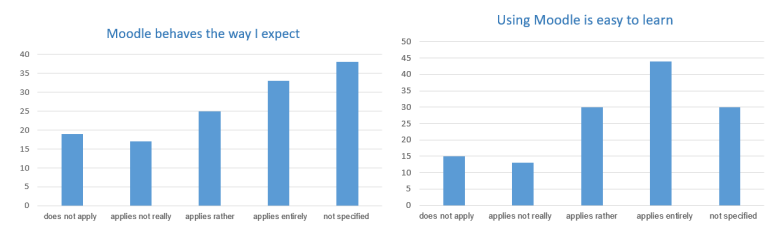

Figure 4: Student feedback

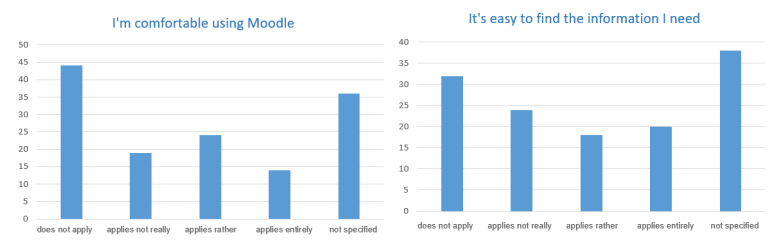

Figure 5: Student feedback

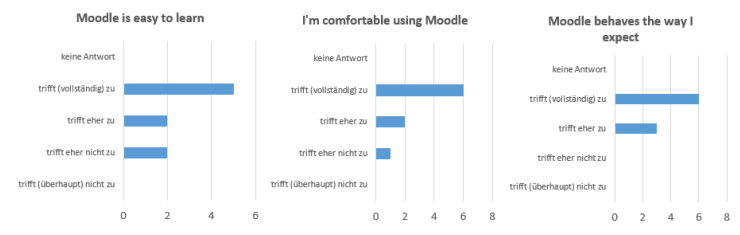

Figure 6: Lecturer feedback

were not comfortable with Moodle and had problems finding information (fig: 5). The comments on the questions show that this is probably related to how the learning materials are structured in Moodle. While in SharePoint based LMS the materials were stored in a library in one place, they are distributed in Moodle and assigned to individual topics.

When asked about possible improvements for Moodle it was often requested that there be an offline synchronization, or a convenient way to download all materials at once to work offline. Another frequently mentioned feature was notifications about new content. In response to the question of what they liked most of all, the performance and the clarity and structure of the virtual learning space were mentioned. At the same time it was rated as a negative point that the virtual courses are unstructured. This shows that the students' opinions about Moodle are partly contradictory. Accordingly, Moodle has been rated by students overall, about a quarter of users find Moodle good to very good, a quarter find Moodle moderate and a quarter think Moodle bad.

The teachers were asked similar questions in the interview. Again, Moodle is easy to learn to use and the behavior of Moodle is as expected. In contrast to the students, the teachers also felt comfortable in operating the system (fig: 6).

Compared to the SharePoint based system, Moodle's functionality is rated as more comprehensive. The use of the systems is seen by the lecturers only as similarly difficult despite a larger range of functions. When asked if Moodle supports teaching better than SharePoint, the teachers' opinion is clearly per Moodle. Overall, Moodle is seen very positively by the teachers (fig: 7). When asked which functions were used by the teachers in the test phase, the 


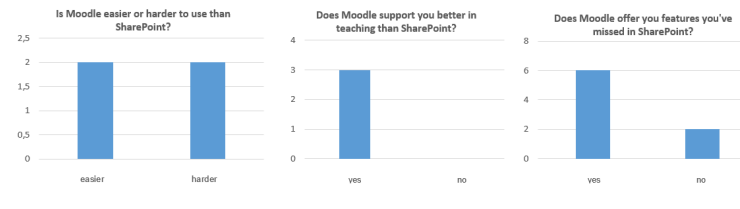

Figure 7: Lecturer feedback

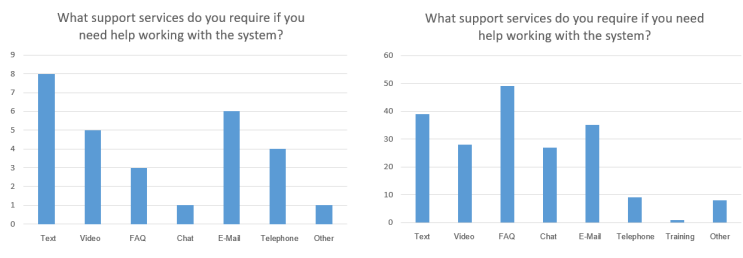

Figure 8: Support services

provision of files and the depositing of hyperlinks were mentioned most frequently. The most often named features that need to be improved are group emails and announcements.

Finally, the students and lecturers were asked about their wishes for support offers (fig: 8). Most frequently mentioned by students were FAQs, text instructions and then came contact with 1st level support by e-mail.

In contrast to the students, FAQs are considered to be less important by lecturers. Instead, videos and telephones are rated higher. Text documentation and e-mail are regarded as important services by both groups.

Besides the comparison of the systems and the feedback from users on usability and features, which is important for the further development of the system, the evaluation also shows that for teachers and students the core functionality of the LMS is the provision and retrieval of files, as well as the distribution of information by e-mail or announcement.

\section{PROJECT SITUATION}

Phase one went off without any major problems. Due to the integration into the existing system and the temporary retention of the organizational structures and support processes, the lecturers and students were confronted with few changes. This made it possible to get objective feedback on the use of Moodle.

In phase two, which has just started, the changes in the allocation of tasks between the specialist department and the IT Center are now coming more to the fore. While users have so far reported few problems with the new system and have given mostly positive feedback, the first problems have arisen in the cooperation.

The specialist department wants to provide the wide range of possibilities that Moodle offers users through developments from the community. At the same time, a large number of adjustments are to be developed in the IT Center to adapt the features available in Moodle to what users are used to from the SharePoint-based LMS. In the IT Center, on the other hand, the focus is on a stable and reliable system. A large number of customizations and plugins make it more complex to maintain and support the system. In addition, this can cause problems when updating the Moodle system. Moodle
Headquarters regularly releases updates from Moodle.To stay up-todate with Moodle at RWTH Aachen University, it must be ensured that all plugins used are also further developed by the community for new Moodle versions. However, since the development in the community is voluntary, it cannot be assumed that the plugins will be developed further in the near future. With the update to version 3.5, a major update is imminent that includes important features for the new European General Data Protection Regulation. Here we will see if all plugins can still be used or if some have to be disabled already. This different orientation means that the specialist department regards the implementation of its requirements as too slow and complicated, while the IT Center regards the need for changes on the part of the specialist department as too great.

So far it has not worked to find a common line to communicate the requirements of the specialist department in a structured way to the developers and system operators in the IT Center. Despite regular meetings for planning the software development and deployments, the requirements are constantly changed at short notice. Communication takes place unstructured via e-mail, support tickets and telephone. The backlog for sprint planning and prioritization is ignored.

Problems also arise in external communication, the specialist department is still responsible for communication with the users, which takes place in addition to 1st level support. But as project project management and 1st level support are now located in the IT Center, close coordination is necessary so that all parties involved are on the same level and can communicate uniformly to users. However, the concepts elaborated to date have not yet been put into practice.

\section{LESSONS LEARNED}

In the course of the project so far, it has turned out that the migration from SharePoint as the basis for the LMS to Moodle poses fewer problems for users than expected. Users get along well with the system. Also technically the operation of the system and the plugin development is a lot of work, but still seems to be a feasible task. The exchange with the Moodle Community at German universities helps in this regard, as we had hoped. However, the new distribution of roles and tasks in the context of the changeover to Moodle is becoming more difficult. As the new governance structures have not yet been implemented, the decision-making processes have not yet been clearly defined. The specialist department has not yet assumed its new role and continues to operate within its usual structures. Due to the different objectives of the IT center and the specialist department, this leads to conflicts in the focus of the project, despite constructive cooperation. An important factor that will be more involved as a regulatory instrument in the future could be the panel of experts representing the users of the system. But until today the expert group has not yet started its work.

\section{REFERENCES}

[1] Hochschulforum Digitalisierung. 2016. Discussion Paper. 20 Theses on Digital Teaching and Learning in Higher Education. Working Paper No. 18. Retrieved April 21, 2018 from https://hochschulforumdigitalisierung.de/sites/default/files/ dateien/HFD_AP_Nr\%2018_Discussion_Paper.pdf

[2] Sarah Grzemski and Ingo Hengstebeck. 2017. Future challenges for qualityassured IT support through cooperative structures. In BOOK OF PROCEEDINGS EUNIS 23rd Annual Congress Shaping the Digital Future of Universities, 
European University Information Systems Organization (Ed.), Vol. 23. European University Information Systems Organization, Muenster Germany, 2-15. https://doi.org/10.17879/21299722960

[3] Ulrik Schroeder, Philipp Rohde, and Michael Gebhardt. 2008. E-Strategy - Strategisches Informationsmanagement fuer Forschung und Lehre, Medien in der Wissenschaft. Medien in der Wissenschaft, Vol. 46. Waxmann Verlag, Muenster, 191-210.
[4] Christian Bischof und Michael Gebhardt und Peter Steves. 2005. Bridging the Gap between Administrative and E-Learning Processes. In Proceedings of the European University Information Systems Conference (EUNIS 2005).

[5] RWTH Aachen University. 2017. Digitalisierungsstrategie der Lehre an der RWTH Aachen. Retrieved April 16, 2018 from http://www.rwth-aachen.de/global/show_ document.asp?id=aaaaaaaaaayitvk 